www.jmscr.igmpublication.org

Impact Factor 5.244

Index Copernicus Value: 5.88

ISSN (e)-2347-176x ISSN (p) 2455-0450

crossref DOI: http://dx.doi.org/10.18535/jmscr/v4i3.17

\author{
Journal Of Medical Science And Clinical Research \\ IGM Publication \\ An Official Publication of IGM Publication
}

\title{
Neglected Posterior Dislocation of Elbow in Childrens
}

\author{
Authors \\ Dr Sridhar Krishnamoorthy ${ }^{1}$, Prof D.Gokul Raj ${ }^{2}$ \\ Corresponding Author \\ Dr Sridhar Krishnamoorthy \\ MS Orthopaedics PG \\ Department of Orthopaedics, Sri Ramachandra Univeristy, Porur, Chennai - 600116 \\ Email: sridhar.krishnamoorthy03@gmail.com
}

\begin{abstract}
Posterior elbow dislocations are very rare in childrens. Elbow dislocations annually affect between 6 and 7 people per 100,000.approximately 90\% of all elbow dislocations seen in the non-dominant upper extremity. Typically, this type of injury is caused by a traumatic fall onto an outstretched arm resulting in a hyperextension injury. Most commonly, the dislocation is associated with a damaged or torn anterior capsule. Posterior elbow dislocation can be classified as simple (74\%) or complex (26\%). A simple dislocation is absent of fractures while a complex dislocation has related fractures. Fractures may exist on the radial head, coronoid process, olecranon, humeral condyles, capitellum or may lead to disruption of the medial collateral ligament, lateral collateral ligament or interosseous membrane. Here, we presenting a case of 14 year old boy, right hand dominant came to the OPD with complaints of pain, swelling and inability to move his right elbow after a fall in outstretched hand 2 weeks back. He was treated indigenously in an outside hospital for 2 weeks. There were no external wounds and no neurovascular involvement. No abnormalities were found in ipsilateral shoulder and wrist joints.Now patient came with above said complaints. He was diagnosed clinically and radiologically to have 2 weeks old neglected right unreduced posterior elbow dislocation.patient was planned for surgerical management after parents consent. He was treated with right elbow open reduced and $V-Y$ lengthening of triceps (SPEEDS PROCEDURE) and internal fixation with $K$ wires. Above elbow pop slab given for 2weeks, following which kwires were removed. He was started on active and passive movements of elbow joint. Patient was followed up for 2 years postoperatively there was full range of movements with no pain or instability, and no valgus or varus deformity was observed.
\end{abstract}

Key words: Ped, Triceps Lengthening, Speeds Procedure

\section{INTRODUCTION}

Traumatic dislocation of the elbow is rare in children with an incidence of only $3 \%$ to $6 \%$ of all elbow injuries. Pure dislocations are uncommon and radiographs must be evaluated carefully for associated injuries, which can include fractures or avulsions of the medical epicondyle, coronoid process, radial head, trochlea and lateral condyle, or disruption of proximal radio-ulnar joint.
Posterior elbow dislocations are very rare in childrens. Elbow dislocations annually affect between 6 and 7 people per 100,000.approximately $90 \%$ of all elbow dislocations seen in the nondominant upper extremity. Typically, this type of injury is caused by a traumatic fall onto an outstretched arm resulting in a hyper-extension injury. Most commonly, the dislocation is associated with a damaged or torn anterior capsule. 
Posterior elbow dislocation can be classified as simple $(74 \%)$ or complex (26\%). A simple dislocation is absent of fractures while a complex dislocation has related fractures. Fractures may exist on the radial head, coronoid process, olecranon, humeral condyles, capitellum or may lead to disruption ofthe medial collateral ligament, lateral collateral ligament or interosseous membrane

\section{CASE PRESENTATION}

Here, we presenting a case of 14 year old boy, right hand dominant came to the OPD with complaints of pain, swelling and inability to move his right elbow after a fall in outstretched hand 2 weeks back. He was treated indigenously in an outside hospital for 2 weeks. There were no external wounds and no neurovascular involvement. No abnormalities were found in ipsilateral shoulder and wrist joints.

Now patient came with above said complaints. He was diagnosed clinically and radiologically to have 2 weeks old neglected right unreduced posterior elbow dislocation.
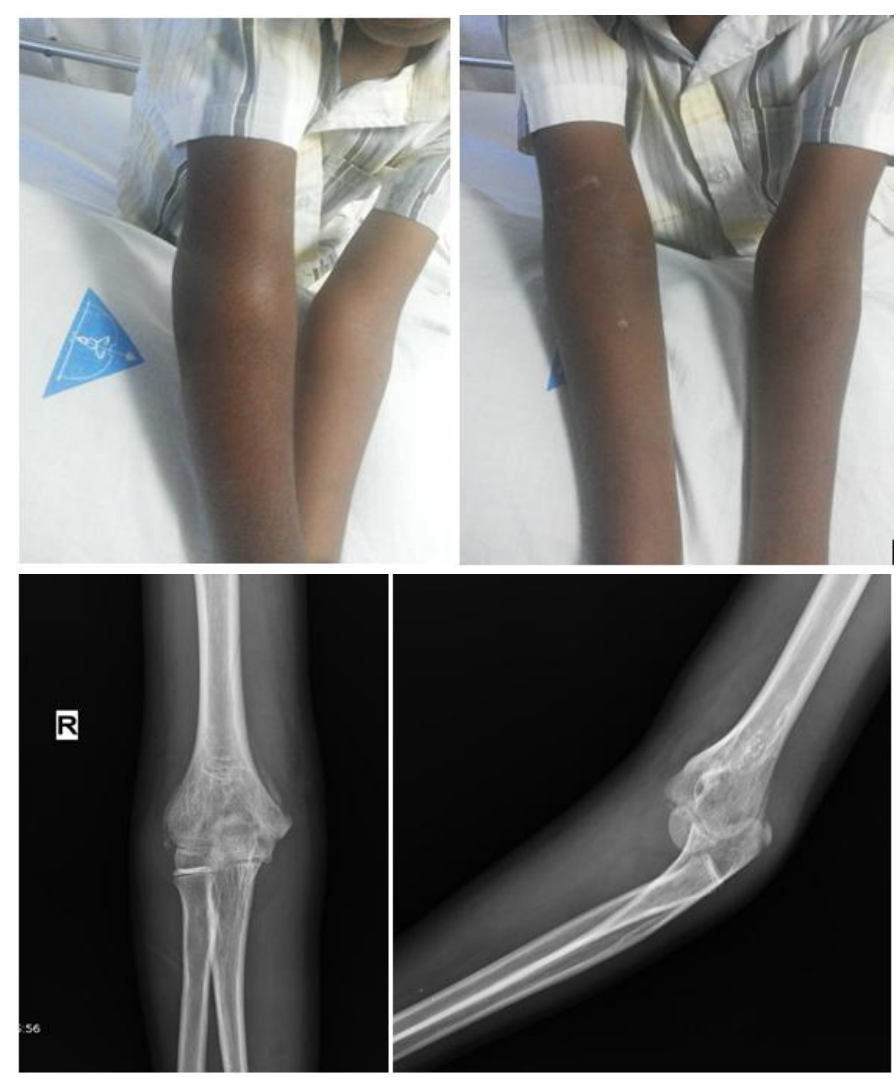

Examiniation revealed no possibility of passive flexion or extension through the elbox joint. A CT scan was performed revealing the intraarticular fragment in the articular surface.

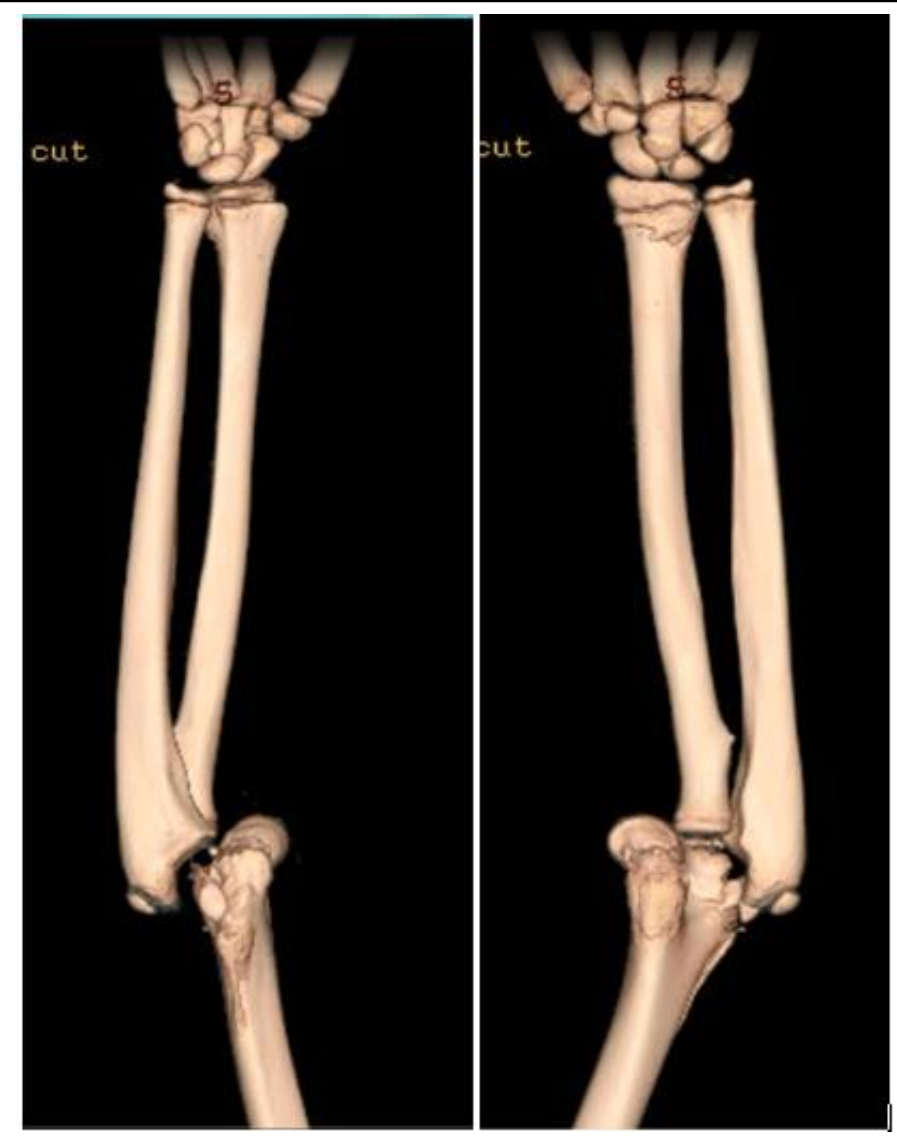

After written consent from the parents, surgery was performed. The patient was placed in left lateral position with the injured elbow on a hand table under general anaesthesia, with a tourniquet and prophylactic antibiotic administration. A middle line approach to the elbow joint was performed and the ulnar nerve was identified and protected. A tear of the origin of the wrist flexors on the medial epicondyle was observed. The epicondylar fragment was removed from the joint and V-Y lengthening of triceps was done through speeds procedure. Open reduction and internal fixation of elbow joint with two $2.5 \mathrm{~mm}$ K-wires under fluoroscopy control. Rigid fixation was achieved. The joint was inspected to be free of any small fragments of bone. Intraoperative testing revealed stability of the joint in the entire range of motion and varus and valgus stress. Postoperatively, a posterior above-elbow splint with the elbow join in $90^{\circ}$ of flexion and neutral rotation was applied for 3 weeks followed by K-wire removal and a physiotherapy program to improve early motion and muscle strength. At 6 months of follow up patient had almost full range of movements with only a lack of 5 degrees of extension and slight atrophy of biceps and triceps 


\section{JMSCR Vol||04||Issue||03||Page 9693-9695||March}

muscles. At one year he restored full range of movements and muscle strength.

\section{INTRA OPERATIVE}
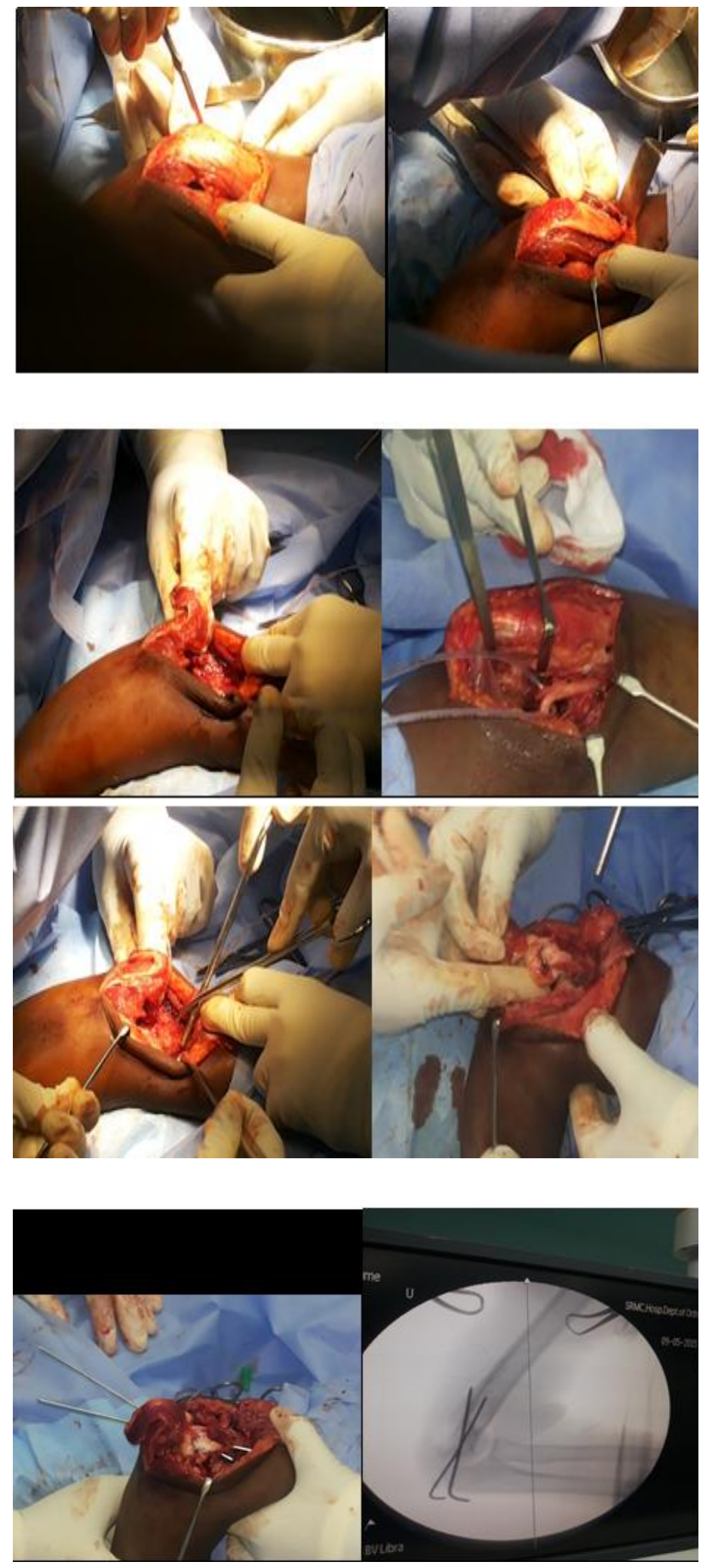

\section{POST OPERATIVE FOLLOW UP}
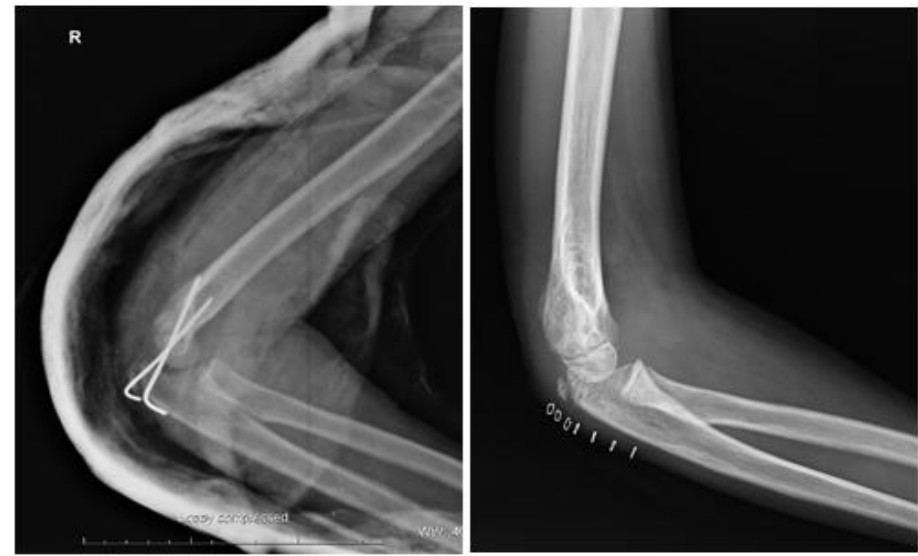

At final follow up at two years postoperatively there was full range of movements with no pain or instability, and no valgus or varus deformity was observed.

\section{CONCLUSION}

Elbow dislocations in children are uncommon. Associated injuries must be suspected. The dislocation should ideally be reduced under general anaesthesia and radiological control to avoid delay in accurate diagnosis

\section{REFERENCES}

1. Fowles JV, Slimane N, Kassab MT: Elbow dislocation with avulsion of the medial humeral epicondyle. J Bone Joint Surg Br 1990, 72: 102-104.

2. Rasool MN: Dislocations of the elbow in children. J Bone Joint Surg Br 2004, 86: 1050-1058

3. Chen H, Tang P, Zhang B: Posterior dislocation of the elbow associated with fracture of the radial head and olecranon, and with medial collateral ligament disruption: a case report. Cases J 2008, 1: 168 